\title{
Floral traits and flowering behaviors of Malaysian rice cytoplasmic male sterile and maintainer lines and its relationship with out-crossing performance
}

\author{
Shahida Hashim ${ }^{1}$, Phebe Ding ${ }^{2}$, Mohd Firdaus Ismail ${ }^{2}$, Asfaliza Ramli ${ }^{1}$ \\ ${ }^{1}$ Malaysian Agricultural Research and Development Institute (MARDI), Penang, Malaysia \\ ${ }^{2}$ Universiti Putra Malaysia, Selangor, Malaysia
}

*Corresponding author: shahida@mardi.gov.my

\begin{abstract}
Rice is a strictly self-pollinating crop. However, in hybrid rice seed production, an effective male sterility system is used to produce hybrid seed in bulk. In hybrid rice system, the pollen grains of cytoplasmic male sterile (CMS) are sterile and the female organ of the CMS depends on the fertile pollen released by the maintainer or restorer lines via out-crossing or cross-pollination in order to produce seed. Floral trait and flowering behavior of CMS and its corresponding maintainer or restorer lines are essential factors in hybrid rice seed production because they influenced the out-crossing or cross-pollination between parental lines. Two local CMSs and their corresponding maintainer lines were developed through breeding program in Malaysian Agricultural Research and Development Institute (MARDI) namely 0025A/0025B and 0047A/0047B. This study was carried out on floral traits and flowering behavior of these two hybrid line. Present studies have shown that there were variations between the CMS and its maintainer lines whether on floral trait or flowering behavior for both hybrid rice combinations. The results showed that stigma characters for both $0025 \mathrm{~A}$ and 0047 were superior than their respective maintainers. Therefore, it is expected that the out-crossing rate would be high. Seeding date intervals need to be done on 0025A/0025B during nursery stage because the on-set of flowering between parental lines was significantly different. Panicle of both CMS was also classified as just exserted and partially-exserted and application of exogenous hormones such as gibberellic acid was useful to improve panicle elongation and consequently increase the seed set and yield. Correlation study indicates that the stigma area of both 0025A and 0047A has significant positive correlation with out-crossing rate.
\end{abstract}

Keywords: anther, flowering, male sterility, rice, stigma.

Abbreviations: CMS_cytoplasmic male sterile; DAT_days after transplanting; OCR_out-crossing rate; SER_stigma exsertion rate; PER_panicle exsertion rate; $\mathrm{GA}_{3}$ gibberellic acid

Introduction

Rice (Oryza sativa Linn.) is a self-pollinated plant where each flower contains both male and female parts. As such, each flower of rice is able to pollinate by itself without the need of other flowers or rice varieties. However, the rate of natural out-crossing or cross-pollination in cultivated rice is relatively low (<4\%) (Hayes et al., 1955; Sahadevan and Namboodiri, 1963) and the success rate is depending much on layout of the field and the local environment conditions (Oka and Morishima, 1967). Unlike cultivated rice, wild Oryza species are known to have a greater out-crossing (0-44\%) than cultivated rice as reported by Sahadevan and Namboodiri (1963), Oka (1988) and Virmani (1994). In 1973, scientists have found a wildabortive cytoplasmic male sterile (WA-CMS) rice plants in Hainan Island. This species are unable to set seed through selfpollination due to their sterile pollen (Marathi and Jena, 2015). Furthermore, this WA-CMS has been used extensively as a main component in three-line hybrid rice system in China due to its good performance in out-crossing rate.
Development of hybrid rice varieties is also conducted in Malaysia through breeding programme in Malaysian Agricultural Research and Development Institute (MARDI) since 1984 (Guok et al., 1998). A number of local cytoplasmic male sterile (CMS) lines have been developed using backcrossing method. Currently, two potential CMS have been identified viz., 0025A and 0047A (Elixon et al., 2013) and as well as their respective maintainers (0025B and 0047B). However, basic information on floral trait, flowering behaviour and pollination process of these two CMS (0025A and 0047A) lines are still lacking. An essential floral characters that influence the out-crossing are percentage of panicle exsertion, angle of floret opening, style and stigma length, stigma breadth, stigma area and stigma exsertion. A number of agronomic characteristics of the plant viz., plant height, flag leaf length and angle and panicle exsertion are also affecting the natural out-crossing (Virmani, 1994). Information on floral traits and flowering behaviors of parental lines may be beneficial to the breeders, plant physiologist and agronomist 
as a guideline to improve flowering synchronization between parental lines during seed production. Hence, this study was conducted to assess and understand the floral traits and flower behaviors of locally developed CMS and its respective maintainer lines and as well as the relationships between the traits and out-crossing performance.

\section{Results}

Female and male reproductive traits of Malaysian CMS and maintainer lines

Analysis of variance shows that there was a significant variation in some of the female and male reproductive traits of 0025A/0025B hybrid rice combination as shown in Table 1. CMS 0025A and its respective maintainer, 0025B are genetically isogenic except for style length and anther length. The stigma length of $0025 \mathrm{~A}$ was $42.2 \%$ longer than the stigma of 0025B (Table 1). The stigma breadth of 0025A was wider than $0025 \mathrm{~B}$ by $100 \%$ with an average of $0.6 \mathrm{~mm}$. The stigma area, which derived from multiplication of stigma length and breadth, was significantly varied between 0025A and 0025B parental lines. The stigma area of 0025A was larger than 0025B by $135.1 \%$.

Result also showed that there was a significant variation between CMS 0047A and its respective maintainer line, 0047B in some of the reproductive traits except for style length, anther length and filament length (Table 2). The stigma of 0047A was longer than 0047B by $90.1 \%$. Results also show that the stigma of $0047 \mathrm{~A}$ was $147.6 \%$ wider than 0047B. The stigma area of $0047 \mathrm{~A}$ was $17 \%$ larger than 0047B.

\section{Flowering behaviors of Malaysian CMS and maintainer lines}

Analysis of variance shows that there was no significant variation between $0025 \mathrm{~A}$ and $0025 \mathrm{~B}$ hybrid rice combination in terms of number of days to initial flowering, angle of floret opening and duration of flowering (Table 3). Among all the flowering behaviors determined, both parental lines only showed significant differences in duration of floret opening. Number of days required for the onset of flowering for both 0025A and 0025B parental lines were quite similar i.e. around 65-66 days after transplanting (DAT), respectively. Duration of floret opening can be defined as a period from opening to closing of florets during flowering. The floret opening of 0025A CMS lasted longer than 0025B by $166 \mathrm{~min}$. Both CMS and maintainer lines took 7 days to complete their flowering process.

Table 4 shows that there was a significant variation between 0047A and 0047B in terms of number of days to flowering and duration of floret opening. The initiation of flowering occurred at 74 DAT for 0047A and it was significantly late than 0047B, which occurred at 65 DAT. Floret of 0047A closed after 183.3 min which lasted longer than 0047B by $109 \mathrm{~min}$. Both 0047A and 0047B had similar duration of flowering, where they took 8 days to complete their flowering process.

Fig 1 shows a pattern of floret opening for both 0025A/0025B and $0047 \mathrm{~A} / 0047 \mathrm{~B}$ parental lines during flowering. Floret opening for both CMS (0025A and 0047A) was earlier than their corresponding isogenic maintainer lines (0025B and 0047B), where it started as early as $1000 \mathrm{~h}$. Both 0025B and
0047B maintainer lines initiated blooming at $1100 \mathrm{~h}$. Observation also found that the peak blooming for both CMS and maintainer lines combination were occurred concurrently, where frequency of opening floret reached the maximum at 1200 and $1300 \mathrm{~h}$ for 0047A/0047B and 0025A/0025B, respectively. Opening of the floret ended at $1500,1400,1500$ and 1330 for 0025A, 0025B, 0047A and 0047B, respectively. This indicated that duration of floret opening for CMS was longer than their respective maintainers.

\section{Others floral trait of Malaysian CMS}

There was a significant variation between CMS 0025A and 0047A in terms of stigma exsertion rate (SER) and out-crossing rate (OCR) as shown in Table 5 . However, panicle exsertion rate (PER) was not differ from each other for both CMS lines.

By referring to the standard evaluation of hybrid rice outlined by Virmani et al. (1997) stigma exsertion of 0025A and 0047A can be classified as fair and good, respectively, where stigma exsertion rate of 0047A was $54.7 \%$ longer than 0025A (Table 5). The out-crossing rate of $0025 \mathrm{~A}$ and $0047 \mathrm{~A}$ was 8.5 and $6.4 \%$, respectively, and these CMS lines can be classified as having poor out-crossing by referring to Virmani et al. (1997). However, 0025A CMS showed better OCR than 0047A by $32.8 \%$. Panicles of $0025 \mathrm{~A}$ and $0047 \mathrm{~A}$ can be classified as combinations of exserted and partially exserted, where only 74.4 and $76.2 \%$ of the panicles protrude from the flag leaf sheath, respectively (Virmani et al., 1997).

\section{Relationships between floral traits and out-crossing rate of CMS 0025A and 0047A}

Correlation coefficients for floral traits with out-crossing rate (OCR) of 0025A and 0047A were computed and presented in Table 6 . In 0025A, the stigma area shows significant positive correlation $\left(r^{2}=0.87\right)$ with OCR. However, other floral traits do not show any significant correlation with the OCR. For 0047A, the stigma breadth $\left(r^{2}=0.87\right)$ and stigma area $\left(r^{2}=0.78\right)$ correlate positively with OCR. The positive correlation is a good indication, where the wider the stigma breadth, the larger the stigma area is available for pollen to be deposited on the stigma.

\section{Discussion}

The superiority of stigma characters in local CMS lines was aligned with the report by Yuan and Fu (1995) who stated that stigma characteristics are the most important floral traits influencing out-crossing in the female parents (CMS line) and it was highlighted as the main criteria in breeding of CMS lines in China. The stigma of both 0025A and 0047A was considered as a good character (Oka, 1988) who's mentioned that CMS lines with a stigma length of more than $1 \mathrm{~mm}$ had a pronounced effect on its out-crossing rate. The longer stigmas increase the capacity and probabilities of the stigma to receive pollen grains released by the anther and consequently increase the chances of pollination. Stigma with a larger size is also a desirable character for female parent because it is known to facilitate better platform and important in interception of air-borne pollen to be deposited on the stigma during cross-pollination (Sheeba et al., 2006). Both local CMS lines had wider stigma 
Table 1. Floral traits of 0025A/0025B lines.

\begin{tabular}{lllllll}
\hline Line & $\begin{array}{l}\text { Stigma } \\
\text { length } \\
(\mathrm{mm})\end{array}$ & $\begin{array}{l}\text { Stigma breadth } \\
(\mathrm{mm})\end{array}$ & $\begin{array}{l}\text { Stigma } \\
\text { area } \\
\left(\mathrm{mm}^{2}\right)\end{array}$ & $\begin{array}{l}\text { Style } \\
\text { length } \\
(\mathrm{mm})\end{array}$ & $\begin{array}{l}\text { Anther length } \\
(\mathrm{mm})\end{array}$ & $\begin{array}{l}\text { Filament } \\
\text { length } \\
(\mathrm{mm})\end{array}$ \\
\hline $0025 \mathrm{~A}$ & $1.92 \mathrm{a}^{\mathrm{z}}$ & $0.62 \mathrm{a}$ & $0.87 \mathrm{a}$ & $0.42 \mathrm{a}$ & $2.47 \mathrm{a}$ & $1.76 \mathrm{~b}$ \\
$0025 \mathrm{~B}$ & $1.35 \mathrm{~b}$ & $0.31 \mathrm{~b}$ & $0.37 \mathrm{~b}$ & $0.41 \mathrm{a}$ & $2.62 \mathrm{a}$ & $3.57 \mathrm{a}$ \\
\hline
\end{tabular}

${ }^{2}$ Means with the same letter within the column are not significant at $P \geq 0.05$ according to DMRT.

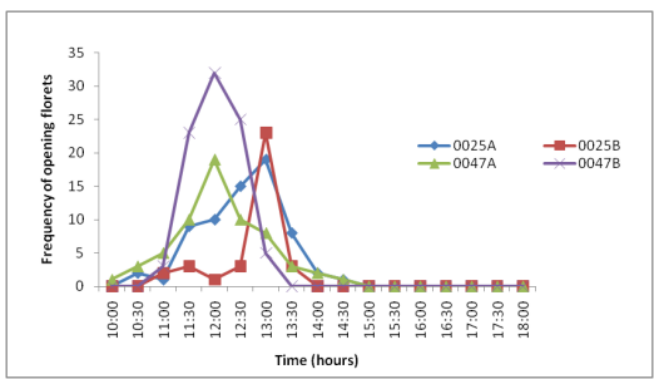

Fig 1. Pattern of opening florets in 0025A/0025B and 0047A/0047B during flowering.

Table 2. Floral traits of 0047A/0047B lines.

\begin{tabular}{lllllll}
\hline Line & $\begin{array}{l}\text { Stigma } \\
\text { length } \\
(\mathrm{mm})\end{array}$ & $\begin{array}{l}\text { Stigma breadth } \\
(\mathrm{mm})\end{array}$ & $\begin{array}{l}\text { Stigma } \\
\text { area } \\
\left(\mathrm{mm}^{2}\right)\end{array}$ & $\begin{array}{l}\text { Style } \\
\text { length } \\
(\mathrm{mm})\end{array}$ & $\begin{array}{l}\text { Anther length } \\
(\mathrm{mm})\end{array}$ & $\begin{array}{l}\text { Filament } \\
\text { length } \\
(\mathrm{mm})\end{array}$ \\
\hline 0047A & $2.11 \mathrm{a}^{2}$ & $0.52 \mathrm{a}$ & $0.55 \mathrm{a}$ & $0.30 \mathrm{a}$ & $2.1 \mathrm{a}$ & $1.1 \mathrm{a}$ \\
$0047 \mathrm{~B}$ & $1.11 \mathrm{~b}$ & $0.21 \mathrm{~b}$ & $0.47 \mathrm{~b}$ & $0.41 \mathrm{a}$ & $2.1 \mathrm{a}$ & $1.2 \mathrm{a}$ \\
\hline
\end{tabular}

${ }^{z}$ Means with the same letter within the column are not significant at $P \geq 0.05$ according to DMRT.

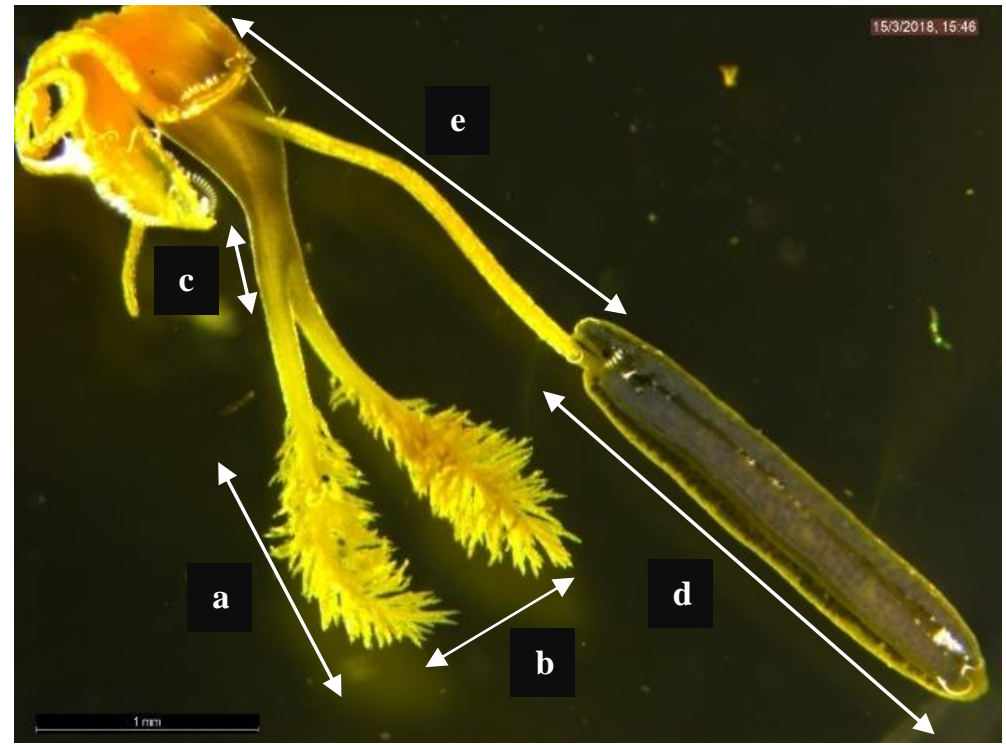

Fig 2. Male and female reproductive parts of rice measured using an ocular meter attached to a light microscope. (a) stigma length, (b) stigma breadth, (c) style length, (d) anther length and (e) filament length. Scale bar: $1 \mathrm{~mm}$.

Table 3. Flowering behaviors of 0025A/0025B lines.

\begin{tabular}{lllll}
\hline Line & $\begin{array}{l}\text { Number of } \\
\text { days to initial } \\
\text { flowering } \\
\text { (day) }\end{array}$ & $\begin{array}{l}\text { Duration of floret } \\
\text { opening } \\
\text { (min) }\end{array}$ & $\begin{array}{l}\text { Angle of floret } \\
\text { opening } \\
\left({ }^{\circ}\right)\end{array}$ & $\begin{array}{l}\text { Duration } \\
\text { of } \\
\text { flowering } \\
\text { (day) }\end{array}$ \\
\hline $0025 \mathrm{~A}$ & $65 \mathrm{a}^{2}$ & $213.3 \mathrm{a}$ & $41.3 \mathrm{a}$ & $7 \mathrm{a}$ \\
$0025 \mathrm{~B}$ & $66 \mathrm{a}$ & $47.3 \mathrm{~b}$ & $41.3 \mathrm{a}$ & $7 \mathrm{a}$ \\
\hline
\end{tabular}

${ }^{2}$ Means with the same letter within the column are not significant at $P \geq 0.05$ according to DMRT. 
Table 4. Flowering behaviors of 0047A/0047B lines.

\begin{tabular}{lllll}
\hline Line & $\begin{array}{l}\text { Number of days } \\
\text { to flowering } \\
\text { (day) }\end{array}$ & $\begin{array}{l}\text { Duration of floret } \\
\text { opening } \\
\text { (min) }\end{array}$ & $\begin{array}{l}\text { Angle of floret } \\
\text { opening } \\
\left({ }^{\circ}\right)\end{array}$ & $\begin{array}{l}\text { Duration } \\
\text { of } \\
\text { flowering } \\
\text { (day) }\end{array}$ \\
\hline $0047 \mathrm{~A}$ & $74 \mathrm{a}^{\mathrm{z}}$ & $183.3 \mathrm{a}$ & $40.8 \mathrm{a}$ & $8 \mathrm{a}$ \\
$0047 \mathrm{~B}$ & $65 \mathrm{~b}$ & $64.3 \mathrm{~b}$ & $40.7 \mathrm{a}$ & $8 \mathrm{a}$ \\
\hline
\end{tabular}

${ }^{2}$ Means with the same letter within the column are not significant at $P \geq 0.05$ according to DMRT.

Table 5. Panicle exsertion, stigma exsertion and out-crossing rates of 0025A and 0047A lines.

\begin{tabular}{llll}
\hline Line & $\begin{array}{l}\text { Panicle exsertion rate } \\
(\%)\end{array}$ & $\begin{array}{l}\text { Stigma exsertion rate } \\
(\%)\end{array}$ & $\begin{array}{l}\text { Out-crossing } \\
\text { rate } \\
(\%)\end{array}$ \\
\hline $0025 \mathrm{~A}$ & $74.1 \mathrm{a}^{\mathrm{z}}$ & $26.7 \mathrm{~b}$ & $8.5 \mathrm{a}$ \\
$0047 \mathrm{~A}$ & $76.2 \mathrm{a}$ & $41.3 \mathrm{a}$ & $6.4 \mathrm{~b}$ \\
\hline
\end{tabular}

${ }^{2}$ Means with the same letter within the column are not significant at $\mathrm{P} \geq 0.05$ according to DMRT.

Table 6. Correlation coefficients ( $r$ ) between out-crossing rate (OCR) and floral traits of 0025A and 0047A lines.

\begin{tabular}{llllllll}
\hline & Stigma length & $\begin{array}{l}\text { Stigma } \\
\text { breadth }\end{array}$ & $\begin{array}{l}\text { Style } \\
\text { Length }\end{array}$ & $\begin{array}{l}\text { Stigma } \\
\text { area }\end{array}$ & $\begin{array}{l}\text { Anther } \\
\text { length }\end{array}$ & $\begin{array}{l}\text { Filament } \\
\text { length }\end{array}$ & OCR \\
\hline & & & & & & & \\
$0025 \mathrm{~A}$ & $-0.04^{\mathrm{NS}}$ & $-0.13^{\mathrm{NS}}$ & $-0.38^{\mathrm{NS}}$ & $0.87^{* *}$ & $-0.17^{\mathrm{NS}}$ & $0.26^{\mathrm{NS}}$ & - \\
$0047 \mathrm{~A}$ & $-0.47^{\mathrm{NS}}$ & $0.87^{*}$ & -0.11 & $0.78^{*}$ & $-0.14^{\mathrm{NS}}$ & $-0.57^{\mathrm{NS}}$ & - \\
\hline
\end{tabular}

${ }_{\mathrm{NS},}^{*},{ }^{* *}$ Non-significant, significant at $\mathrm{P} \leq 0.05$, significant at $\leq 0.01$.

Table 7. Classification of stigma exsertion rate (SER), panicle exsertion rate (PER) and outcrossing rate (OCR) according to Virmani et al. (1997).

\begin{tabular}{ll}
\hline PER (\%) & Description \\
\hline$>70$ & Excellent \\
$41-70$ & Good \\
$21-40$ & Fair \\
$11-20$ & Poor \\
$0-10$ & Unacceptable \\
& \\
\hline SER (\%) & Description \\
\hline 100 & Well exserted \\
$90-99$ & Moderately exserted \\
$75-89$ & Just exserted \\
$60-74$ & Partially exserted \\
$<59$ & Enclosed \\
& \\
\hline OCR (\%) & Description \\
\hline$>35$ & Excellent \\
$25-35$ & Good \\
$15-25$ & Fair \\
$5-15$ & Poor \\
$0-5$ & Unacceptable \\
\hline
\end{tabular}

area than their respective maintainers. Thus it is expected that the CMS may receive sufficient number of pollen grains that to be deposited on the stigma papillae of each floret. Generally, it is known that most of the CMS lines were derived from the wild rice with abortive pollen source (WA-CMS) that were discovered on Hainan Island in 1973 (Marathi and Jena, 2015). This wild Oryza species have a larger stigma, longer style, greater exsertion of stigma and longer period of spikelet opening than the inbred rice in order to have greater ability for out-crossing (Sahadevan and Namboodiri, 1963; Oka, 1988 and
Virmani, 1994). It was believed that both local CMS lines used in this study were also derived from WA-CMS as described by Elixon et al. (2013); thus, having similar floral traits as others WA-CMS. This study also revealed that the respective maintainer of $0025 \mathrm{~A}$, that is $0025 \mathrm{~B}$, was superior to its CMS by having longer filament length. As a pollen parent, the long filament is needed in the maintainer lines as it helps in protruding the anther out from the floret and consequently increases the chances of pollen to be deposited on the stigma of the CMS. There was no significant difference in filament 
length between 0047A and 0047B parental lines (Table 2). Therefore, it is expected that the out-crossing rate of $0047 \mathrm{~A} / 0047 \mathrm{~B}$ combination might be poorer than the 0025A/0025B combination.

The present study revealed that the on-set of $0025 \mathrm{~A} / 0025 \mathrm{~B}$ flowering was quite similar indicating these two parental lines might have good synchronization in flowering. Thus, the lines can be sown simultaneously during preparation at nursery stage. However, the significant difference recorded in number of days to flowering for 0047A and 0047B (Table 4) indicating non-synchronization in flowering may occur if both parental lines are sown simultaneously during nursery preparation. Hence, staggered sowing has to be implemented to this hybrid rice line combination. Generally, it is understood that the CMS line is identical to its corresponding maintainer line. In fact, the CMS line and its respective maintainer may be considered "twin". However, they may differ in some characteristics (Yuan and Fu, 1995).

From the findings of this study, both CMS lines (0025A and 0047A) had longer floret opening duration their respective maintainers (Table 3 and 4). Saran et al. (1971) found that the duration of floret opening was positively correlated with the percentage of sterility. Young (1983) also found out that CMS lines with complete pollen sterility had longer blooming duration than their corresponding maintainer lines in possessing normal pollen fertility. Prolonged duration of floret opening in CMS lines enable the well-exserted stigma to intercept easily with the airborne pollen (Ghorban et al., 2006). Incomplete panicle exsertion of CMS is the impediments in hybrid rice seed production because this character hinders pollination during flowering stage (Yin et al., 2007). The enclosed panicles in the flag leaf sheath may reduce the chances of pollination between the CMS and maintainer lines and consequently lead to low seed setting. In present study, panicles of both local CMS (0025A and 0047A) can be classified as exserted and partially exserted, where only $72-79 \%$ of the panicles protrude from the sheath (Table 5). This indicated that the remaining balance of the panicles, which is hidden inside the leaf sheath may have low possibilities of being fertilized and indirectly affected the grain yield. Improvement in panicle elongation of local CMS line could be done using an exogenous gibberelic acid $\left(\mathrm{GA}_{3}\right)$ that was proven as a successful approach in increasing grain yield of hybrid rice seed production in China (Duan and Ma, 1992). Stigma exsertion rate (SER) is being emphasized as an important trait that contributes to the improvement of seed production in hybrid rice and it is closely related to seed productivity in hybrid rice (Kato and Namai, 1987; Sheeba et al., 2006; Takano-Kai et al., 2011). It is known that exserted stigmas still have a chance of being fertilized even though the floret opening duration has over and the floret has closed. Pollen grain released by the anther of male parent such as the maintainer line may be deposited on the exserted stigma and chances of pollination are still high. From the findings of this study, both local CMS (0025A and 0047A) possessed fair and good stigma exsertion. This trait is beneficial to both CMS because florets with protruding stigma had higher seed set percentage than those without (Kato and Namai, 1987; Ramalingam et al., 1997).

In CMS seed production, the out-crossing rate (OCR) is the final output derived from the successful pollination between the CMS and maintainer lines. The OCR of both local CMS lines
(0025A and 0047A) can be categorized as poor because only 7.3-9.7 and 5.7-7.1\% of the floret was successfully set during flowering, respectively. Virmani et al. (1997) described that promising CMS should have stable pollen sterility, good phenotypic acceptability, $10-30 \%$ seed set during crosspollination and panicle exsertion rate of $90-100 \%$. However, a good cross-pollination or out-crossing can be achieved by adopting a few techniques to encourage flowering synchronization such as seeding interval between parental lines (Virmani and Sharma, 1993; Yuan and Fu, 1995), application of gibberellic acid to improve panicle elongation (Gavino et al., 2008; Rahman et al., 2012; Susilawati et al., 2014), supplementary pollination using rope or bamboo sticks (Virmani and Sharma, 1993) and the most important part is identifying the basic floral traits and flowering behaviors of both parental lines (Virmani et al. 1997; Rahman et al. 2012).

Correlation analysis has shown that the out-crossing rate of 0025A was influenced by the stigma area (Table 6). Larger surface area of 0025A's stigma will attract more pollen to deposit and consequently increase the chances of pollination and finally lead to good seed setting. The out-crossing of 0047A was also positively correlated with the area of stigma and as well as the stigma breadth (Table 6). Savitha et al. (2017) also reported that stigma breadth had a significant positive correlation with number of filled grain per panicle in hybrid rice seed production, indicating that increased stigma breadth in gynoecium will increase number of pollen deposit on the stigma.

\section{Materials and methods}

\section{Planting materials and nursery management}

The study was conducted at a plant house of Centre of Excellent for Rice, MARDI Seberang Perai $\left(5.54{ }^{\circ} \mathrm{N}, 100.47^{\circ} \mathrm{E}\right)$ using completely randomized design with three replications. Two combinations of locally developed hybrids namely 0025A/0025B and 0047A/0047B were obtained from Gene Bank, MARDI Seberang Perai, Penang, Malaysia and were used in this study. The seeds of CMS lines (0025A and 0047A) were sown concurrently with their respective maintainer lines (0025B and 0047B). Seedlings of each line were raised in bed under saturated soil condition and 18 -year-old seedlings were then manually transplanted to the pot with a dimension of $1 \mathrm{~m}$ $\times 1 \mathrm{~m} \times 0.5 \mathrm{~m}$. The row proportion or row ratio refers to the number of rows of the maintainer line to that of the CMS line in a CMS seed production plot. In this study, the row ratio was $2: 5$ with spacing of $10 \mathrm{~cm} \times 10 \mathrm{~cm}$ and $15 \mathrm{~cm} \times 15 \mathrm{~cm}$ between the CMS and maintainer lines, respectively. Single seedling of CMS and two seedlings of maintainer were transplanted per point. Pest, disease and crop maintenance were monitored according to the standard practices suggested in Manual Teknologi Penanaman Padi Lestari (Azmi et al., 2008).

\section{Data collection}

Ten plants per replication of each CMS and maintainer lines were selected randomly during flowering to maturity stage for measurement of floral traits and flowering behaviors. Parameters such as panicle exsertion rate, stigma exsertion rate and out-crossing rate were recorded for CMS but not on 
maintainer lines (0025B and 0047B) since the maintainers are inbred lines, that have natural self-pollination and full exserted panicle and stigma.

Determination of female and male reproductive traits of Malaysian CMS and maintainer lines

Stigma length, stigma breadth, style length, anther length and filament length was shown in Fig. 2 were measured during flowering stage using an ocular micrometer (EOM 11, ERMA, Japan) attached to a light microscope (ML5050, Meiji Techno, Japan) according to Sheeba et al. (2006). The stigma area was computed using the length and breadth of the stigma and expressed in $\mathrm{mm}^{2}$.

\section{Determination of stigma exsertion rate of CMS}

Stigma exsertion rate (SER) was recorded after flowering stage according to Virmani et al. (1997) and it was determined by counting number of florets showing exserted stigma on one or both sides of the florets to the total numbers of floret. SER was calculated using the following formula and expressed in percentage.

SER $(\%)=\frac{\text { number of floret with exserted stigma }}{\text { total number of florets }} \times 100$

The SER of the plant were then characterized according to Virmani et al. (1997) as shown in Table 7.

\section{Determination of panicle exsertion rate of CMS}

Panicle exsertion rate (PER) was measured at maturity according to Virmani et al. (1997) and it was referred to the proportion of the panicle that is exserted from the flag leaf to the total panicle length. PER was calculated using the following formula and expressed in percentage.

PER $(\%)=\frac{\text { length }(\mathrm{cm}) \text { of exserted panicle }}{\text { total length }(\mathrm{cm}) \text { of panicle }} \times 100$

The panicle of the plant was then characterized according to Virmani et al. (1997) as shown in Table 7.

\section{Determination of out-crossing rate of CMS}

The out-crossing rate (OCR) was determined at maturity stage and it was referred to the extent of seed set on open pollinated panicle, which is expressed in percentage.

OCR $(\%)=\frac{\text { number of filled grain }}{\text { total number of spikelet }} \times 100$

The performance of OCR was described according to Virmani et al. (1997) as shown in Table 7.

\section{Number of days to initial flowering}

Number of days to initial flowering was observed when panicles protrude from the sheath in $5 \%$ of the plant (Virmani et al., 1997).

\section{Duration of floret opening}

Duration of floret opening was recorded from opening to closing of florets during flowering (Virmani et al., 1997).

\section{Angle of floret opening}

Angle of floret opening was measured in degree using a protractor during flowering stage. It was taken as the separation angle between the glumes of a floret (Sheeba et al., 2006).

\section{Duration of flowering}

Duration of flowering was recorded from the beginning until the end of the day of anthesis (Virmani et al., 1997).

\section{Frequency of opening florets}

Frequency of opening florets for both parental lines was observed from $10 \mathrm{am}$ to $6 \mathrm{pm}$ with $30 \mathrm{~min}$ time interval according to Parmer et al. (1976) with slightly modifications.

\section{Statistical analysis}

Data were tabulated and SAS version 9.3 (SAS Institute 2011, Gary, NC) was used to analyzed the data using analysis of variance (ANOVA). Mean differences were compared by Duncan's multiple range test at $5 \%$ level of significance (Steel and Torrie, 1980). The associations between the selected parameters were analyzed using correlation analysis by means of Pearson's correlation matrix.

\section{Conclusion}

We report that both CMS and maintainers have different characters in terms of some floral traits and flowering behaviors. The respective variations between the CMS and maintainer lines are useful for the plant to adapt themselves during pollination. The female reproductive parts (stigma) of both CMS were significantly longer, broader and wider than their respective maintainers. These characters are essential to the CMS so that higher number of pollen supplied by the maintainer line can be deposited on the stigma and led to higher chances of pollination. Correlation analysis has shown that the stigma area of 0025A and 0047A was significantly associated with the out-crossing rate. This indicated that the possibility of more pollen to be deposited on the larger stigma area is high. Results also showed that the on-set of flowering for combination of 0025A and 0025B was similar, indicating that both parental lines can be sown simultaneously in order to get good flowering synchronization. However, the on-set of flowering for both 0047A and 0047B was significantly different. It is expected that the problem of flowering synchronization between these parental lines might be occurred for this hybrid 
rice combination. The panicle of both CMS can be classified as having poor exsertion because $21-28 \%$ of the panicle was hidden within the leaf sheath. The character of poor panicle exsertion will limit the chances of out-crossing and consequently reduce the grain yield. Hence, application of plant growth regulator or hormone such as gibberellic acid $\left(\mathrm{GA}_{3}\right)$ may be used to improve the panicle elongation of Malaysian CMS.

\section{Acknowledgements}

The authors would like to acknowledge Putra Grant (GP-IPS) given by Universiti Putra Malaysia (UPM/700-2/1/GPIPS/2016/9487300) for funding this project.

\section{References}

Azmi M, Alias I, Abu Hassan D, Ayob AH, Azmi AR, Badrulhadza A, Maisarah MS, Muhammad H, Othman O, Saad A, Sariam O, Siti Norsuha M, Yahaya H (2008) Manual teknologi penanaman padi lestari, MARDI Press, Serdang.

Duan XM, Ma HS (1992) Effects of gibberellic acid application on seed yield and quality of hybrid rice. Seed Sci Technol. 20:209-214.

Elixon S, Mohd Solihen J, Asfaliza R, Othman O, Marzukhi H, Allicia J, Maisarah MS (2013) Penilaian ciri morfologi dan fisiko-kimia ke atas titisan CMS (cytoplasmic male sterile) 0025A/B dan 0047A/B. In: Marzukhi H (ed) Prosiding persidangan padi kebangsaan 2013. Persidangan padi kebangsaan, Penang, Dec. 2013.

Gavino RB, Pi Y, Abon Jr, CC (2008) Application of gibberellic acid $\left(G_{3}\right)$ in dosage for three hybrid rice seed production in the Philippines. J Agric Technol. 4(1):183-192.

Guok HP, Azlan S, Ku Yahaya KH (1998) Developing hybrid rice technology in Malaysia. In: Virmani SS, Sid EA, Muralidharan $\mathrm{K}$ (eds) Proceeding of the $3^{\text {rd }}$ international symposiun on hybrid rice, Hyderabad, Nov 1996. Hayes HK, Immer FR, Smith DC (1955) Methods of plant breeding, McGrow Hill Book Co, New York.

Kato H, Namai H (1987) Floral characteristics and environmental factors increasing natural outcrossing rate for $F_{1}$ hybrid seed production. Jpn J Breed. 37:75-84.

Marathi B, Jena KK (2015) Floral traits to enhance out-crossing for higher hybrid seed production in rice: Present status and future prospects. Euphytica. 201:1-14.

Oka HI (1988) Origin of cultivated rice, Jpn Sci Soc Press, Tokyo. Oka HI, Morishima H (1967) Variations in the breeding systems of wild rice, Oryza penniis and Oryza sativa. Evolution. 15:418-430.
Parmer KS, Siddiq EA, Swaminathan MS (1976) Variation in components of flowering behaviour of rice. Indian J Genet PI Br. 39(3):542-550.

Rahman MH, Khatun MM, Khan MSR, Mian MAK, Rasul MG (2012) Effects of $\mathrm{GA}_{3}$ and row ratio of restorer (R) and CMS lines $(A)$ on different characters and seed production of BRRI hybrid Dhan. Bangl J Agric Res. 37(4):665-676.

Ramalingan J, Nadrajan N, Vanniarajan C, Rangsamy P (1997) Floral traits influencing outcrossing rate in rice. Int Rice Res Notes. 22:18-19.

Sahadevan DC, Namboodiri KMN (1963) Natural crossing in rice. Proceeding Indian Academy Science Sector B58: 176185.

Saran HS, Sahu SP, Azam MQ (1971) Sterility due to abnormal functioning of lemma and palea in IR5/189-1-3 rice (Oryza sativa, L). Indian J Agr Sci. 41:515-519.

Savitha P, Ushakumari R, Vanniarajan C (2017) Correlation between selected morphological floral characters and yield components related traits in Oryza sativa L. Indian J Exp Biol. 55:642-647.

Sheeba A, Vivekanandan P, Ibrahim SM (2006) Genetic variability for floral traits influencing out-crossing in the CMS lines of rice. Indian J Agr Res. 40(4):272-276. Steel RGD, Torrie JH (1980) Principles and procedures of statistics, $3^{\text {rd }}$ edn. McGraw-Hill, New York.

Susilawati PN, Surahman M, Durwoko BS, Suhansi TK (2014) Effects of $\mathrm{GA}_{3}$ concentration on hybrid rice seed production in Indonesia. Int J Appl Sci Tec. 4(2):143-148.

Takano-Kai N, Doi K, Yashimura A (2011) GS3 participates in stigma exsertion as well as seed length in rice. Breeding Sci. 61:244-250.

Virmani SS (1994) Heterosis and hybrid rice breeding. In: Frankes R, Grossman BM, Linskens WHF, Maliga NP, Riky PR (eds) Monographs on theoretical and applied genetics, Vol. 22. Springer-Verlag, Berlin.

Virmani SS, Sharma HL (1993) Manual for hybrid rice seed production. IRRI, Manila

Virmani SS, Viraktamath BC, Casal CL, Toledo RS, Lopez MT, Manalo JO (1997) Hybrid rice breeding manual. IRRI, Manila.

Yin C, Gan L, Ng D, Zhou X, Xia K (2007) Decreased panicles derived indole-3-acetic acid reduces gibberellins $A_{l}$ level in the uppermost internodes, causing panicle enclosure in male sterile rice Zhenshen 97A. J Exp Bot, 58:2441-2449.

Young JB (1983). Cytoplasmic-genetic male sterility and fertility restoration in rice. MS Thesis, Faculty of the Graduate School, University of the Philippines at Los Banos, Laguna, Philippines

Yuan LP and Fu XQ (1995) Technology of hybrid rice production. FAO. 